\title{
Anti-Aging and Biomedicine: Critical Studies on the Pursuit of Maintaining, Revitalizing and Enhancing Aging Bodies
}

\author{
Antje Kampf • Lynn A. Botelho
}

Received: 2 June 2009/Accepted: 24 September 2009/Published online: 10 October 2009

(C) Springer Science+Business Media B.V. 2009

\begin{abstract}
Anti-aging, the idea that medical or quasi-medical concepts can intervene in the aging process to slow, stop, or even reverse the process of growing old, has become a popular and scientific buzz-word throughout the Western world. This special issue focuses specifically on biomedicine and its relation to anti-aging cultures by contextualising this complex topic through an interdisciplinary approach that draws upon ethics, cultural anthropology, sociology, and history to offer a new understanding of biomedicine as a social and cultural practice as it engages with Western society's quest for longevity. Emphasising the historical and sociocultural context of the way anti-aging movements have constructed aging bodies and the aging process, a number of key themes are identified: the competing definitions of old age within biomedicine, medicalisation of old age, the ethics of the anti-aging market, and the contested nature of anti-aging as a legitimate field of gerontology. Suggestions for further research areas for the study of anti-aging medicine and its role in western society are developed, specifically: the need to contrast the science and biomedicine of antiaging with those who are experiencing
\end{abstract}

A. $\operatorname{Kampf}(\bowtie)$

Johannes Gutenberg-Universität Mainz, Mainz, Germany

e-mail: antje.kampf@uni-mainz.de

L. A. Botelho

Indiana University of Pennsylvania, Indiana, PA, USA this "targeted" age, paying closer attention to the different stages of old age and to the gender dynamic involved, considering the social and economic differences found amongst the elderly, and analysing the role of the media in forming and shaping antiaging and biomedicine discourses. The papers in this special issue illustrate the multifaceted nature of anti-aging in the field of biomedicine and its related shifting of the meaning of old age.

Keywords Anti-aging medicine $\cdot$ Biomedicine Old age $\cdot$ History $\cdot$ Ethics $\cdot$ Aging bodies

"All the physiological stigmata of old age have been abolished .... at sixty our powers and tastes are what they were at seventeen." (Huxley 1932, p. 48)

"Aging is not growth and perspective. Aging is arthritis, heart disease, and Alzheimer's dementia;..." (Fossel 2003, p. 71)

As aging populations continue to grow along with the medical promise of greater longevity, the image of the aging body has become an increasingly common image in Western societies. While the rapid demographic aging has raised contemporary debate about the financial and ethical "burdens" of aging bodies to the health care system, anti-aging has also emerged as a popular movement for promoting activity, mobility and life-style choice to counter 
traditional images of decline and decrepitude. Antiaging is the idea that medical or quasi-medical concepts can intervene in the aging process to slow, stop, or even reverse the process of growing old. Recent critiques of the anti-aging movement have interpreted the biomedical field involved with the movement as representing a critical shift from biomedicine as a profession occupied with healing bodies to that of enhancing bodies. The standards of biomedical anti-aging vary, but they hold in common the goals of painless functionality and timeless performance (Burri and Dumit 2007).

With this themed issue we invite readers to rethink the positions within the anti-aging medicine debate that are so often portrayed in terms of narrow binaries and opposites. We propose instead that a continuum of pursuits in anti-aging, and, following Binstock (2003), the anti-aging movement can be thought of as shaped by the "boundary work" of different fields. In fact, the reiterated distinctions within cultures of aging that deal with health and disease, normal and pathological, are historically not that clear cut.

The desire to extend the human life course indefinitely in order to achieve immortality is an ancient component of human history, yet is as varied through time as constructions of the relationship between old age, health and disease. The classical understanding of old age, beginning with Aristotle, was based on the concept of humours (blood, phlegm, yellow and black biles) linked to the four elements (earth, water, air, and fire). As people aged, the body's vital heat was burned away and death was the moment of its complete consumption. Consequently, one's humoural make-up shifted over the life course until one became cold and dry in extreme or advanced old age. Critical to this understanding of old age was the awareness that life, and one's stage in it, was placed somewhere on a continuum. Consequently, there were 'degrees' of old age, just as there were stages of childhood and youth.

While sharing a humoural understanding of the body, classical authors did not necessarily share an understanding of old age. Aristotle conceived of old age in relentlessly negative terms, comparing its attributes to the idealized stage of middle age. Hippocrates, too, centred his commentary on the ailments of age, but argued that the condition of old age was cold and moist, and not cold and dry as Aristotle claimed. Galen convincingly defeated
Hippocrates regarding old age's dry nature; however, Galen and Seneca the Younger remained at odds over whether old age was a natural condition or a 'disease'. Throughout most of the ancient period, old age was commonly understood to be a 'diseased state'. In fact, Seneca called it an incurable one. Galen, however, took a different view and argued that old age was a natural process and therefore not an illness, even though old age was certainly not considered a state of perfect health. According to Galen, aging was a distinct condition unto itself and his humoural model would hold primacy of place in medical culture well into the seventeenth century. Within this model the maintenance of good health and the pursuit of a long life depended upon a harmonious balance between humours and elements (cf. also Gruman 1966).

The study of prolongevity received a renewed interest during the Renaissance, ${ }^{1}$ when writers and readers inspired by Galenic theory elaborated regimes of diet, exercise, and lifestyle to attain longevity Adding to these ideas the Enlightenment's dramatic change in scientific thought contributed an overall shift in the ancient understanding of aging as a humoural inequilibrium to a new more mechanical perspective. ' Here, 'Man' was no longer to be understood as solely a divinely wrought animal, but rather as something much more complex and culturally shaped through reason and action.

The rapid modernization of the nineteenth century recast questions of longevity in terms of the physical stress and mental fatigue threatened by the rigors of the industrial era. Drawing on a Social-Darwinist view of the evolution of species, some researchers were confident that (what Lankester called) the more highly civilized races of man would achieve longer lives. ${ }^{3}$ Yet, the evolution of species did not, by definition, imply a pre-determined path or outcome. A changing species could evolve backwards, and the idea of degeneration of the human species concerned nineteenth century writers and social commentators, although the promise of increased life-span and improved health were the hallmarks of the day.

\footnotetext{
$\overline{{ }^{1} \text { For example }}$, by the influential writings of Luigi Cornaro or Cornarus (1475-1566).

2 For example, Robinson (1725).

3 For example, Lankester (1870).
} 
It was also the nineteenth century that saw a rise in the specialization of life sciences and medical disciplines. However, we would like to shift the emphasis away from the commonly made distinction between the emerging gerontology and geriatrics and focus instead on their connections, Contributing to the development of geriatrics, a new medical speciality for old age, Ignatz Leo Nascher, who coined the term, observed the degeneration of organs and tissues in all old bodies (Nascher 1919, pp. 3-4). Nascher also referred to senescence as "normal". Elie Mechtnikoff, who in 1903 invoked the concept 'gerontology', concentrated on the social, psychological and biological aspects of aging, while still asserting in the end that senescence was a disease (cf. Cole 1992; Achenbaum 1995, pp. 23-32). Echoing some of the debates of the Classical Period about whether or not old was a disease, modern scholars and commentators continue to argue about the nature of old age, as well as the form and functions of the medical response to it. In the popular realm, new and additional 'rejuvenation' therapies were invented with the promise that medicine could reduce age-related disease and at least slow, halt or even reverse the biological process of aging: The neurologist Charles Edward Brown-Séquard promised salvation through the injection of animal sex glands, a hypothesis that gained remarkable public interest in the late nineteenth century. His work stimulated a rejuvenation frenzy beginning in the 1920s with the "medical therapy" of transplanting gonads in order to invigorate one's health and turn old bodies into youthful ones (Haber 2004, pp. 51617; Sengoopta 2006; Stoff 2004) This development was followed by Denam Harman's free-radicaltheory of the 1950s that triggered subsequent applications of Vitamin C to extend one's (healthy) life-span. More recently, we have the hormonereplacement therapies popular since the 1960s. By the late twentieth century, the medical approach to a "healthy", disease-free old age had become a powerful goal and incentive for many lay people and scientists and a promising path in the quest towards longevity.

Thus medicine for aging and anti-aging medicine have emerged in tandem. Anti-aging medicine now draws heavily upon research into molecular, endocrine and cell activity and an array of technologies and theories such as nanotechnology, stem cell research, genetic enhancement, neuro-endocrinal theory, and pharmacotherapy. While increasingly defining age as a major risk factor for the development of Alzheimer's dementia, cardio vascular diseases, cancer, and diabetes (DePinho 2000), medicine offers a range of therapies to reduce or halt the diseases of old age by focussing on prevention. Much of the agency of such pre-emptive behaviours is placed on the elderly themselves, and taking care of one's (diseasefree) aging has become a vital component of public health campaigns, such as in Germany (Bundesministerium für Gesundheit und Soziale Sicherung 2004). The German governmental policy for long term health care and pension plans, as well as its biomedical emphasis on biomedicine on prevention, require individuals to develop their own strategies of aging that often include the notion of "risk of age".

The above very brief historical and cultural background provides an introduction to the theme of this special issue on "Anti-aging and biomedicine: Critical studies on the pursuit of maintaining, revitalizing and enhancing aging bodies". The articles offer a theoretical grounding of this anti-aging discourse, as well as a contextualization of this complex topic through an interdisciplinary approach that draws upon ethics, cultural anthropology, sociology, and history. The goal is to widen the understanding of biomedicine as a social and cultural practice as it engages with Western society's quest for longevity. Based on this journal's approach that medicine is a "phenomenon emerging from the matrix of distributed knowledge, new technologies, shifts in economic of health care, the politics of medicine, and a variety of related interests" (Paul 2009 , p. 8), the contributors of this themed issue probe the historical, ethical and theoretical debates that engulf anti-aging biomedicine.

From the range of important topics in these debates we have identified four major, interrelated themes: (a) the competing definitions of old age within biomedicine, (b) the medicalisation of old age, (c) the ethics of the anti-aging market, and (d) the contested nature of anti-aging as a legitimate field of gerontology. ${ }^{4}$ Specifically, this collection of essays

\footnotetext{
$\overline{4}$ We understand this list of themes not to be inclusive, as there are a range of other key themes within anti-aging medicine equally important and under-studied, but due their complexity they are beyond the scope of this issue and may require a whole
} 
engages with the recent critique of the Anti-Aging movement and its proponents' claims and ambitions to overcome old age, along with the movement's inherent ageism and restrictive perspectives on lifestyle choices (Vincent et al. 2008). Drawing upon Vincent et al.'s call for greater social and cultural understanding of the Anti-Aging Movement by examining how it constructs old age and the aging process, this themed issue focuses specifically on biomedicine and its relation to anti-aging cultures. We hope to get away from simplistic accounts of anti-aging medicine cultures that are preoccupied with boundary issues. In doing so, we also offer an expanded and independent analysis, as well exploring how to move forward by considering the range of future scenarios for the elderly and drawing upon the Western historical context and raising the ethical issue of access to life-prolonging medicine based on class and/or wealth. ${ }^{5}$

1. Central to any discussion on anti-aging medicine is how we define old age. As outlined above, the meanings which have become assigned to aging bodies are historically defined and socially inscribed. Current studies have opposing views as to whether old age constitutes disease and material decline or healthy and normal development. However, in both cases aging has become available as open for medical treatment, preventative therapy, and enhancement technologies. Even within the decline model there are debates as to whether decline and deficits should be seen as natural and inevitable parts of the human life course, or as lying outside of the realm of medicine and constitute more of a scientific endeavour (Gubrium 2005; Featherstone 1995). The anti-aging movement and medicine inherits

\footnotetext{
Footnote 4 continued

journal to themselves. Neuroscience, memory medicine and the concept of "enhancement" would fall under this category. A good introduction to this aspect can be found in (Katz and Peters 2008). Similarly, we have not touched upon the important key theme of anti-aging and disability: how is the anti-aging approach dealing with and responding to old people who are disabled? And what are the implications for the concept of enhancement? In fact, what has been the (global) impact of anti-aging biomedicine on the benefit of healthy old age?

5 An analysis by researchers closer to the anti-aging cultures can be found in (Lucke et al. 2009).
}

the philosophical (and religious) views about the aging body as an entity (Katz 2005, Vincent 2003), shaped by views of old age from the vantage point of the young (Haber 2004). At the same time, anti-aging culture promotes the notion that decline, decrepitude, and immobility can be contested if aged bodies are understood in terms of activity and mobility. Although such a view potentially empowers aging persons, it also renders the experience of declining bodies irrelevant and thus makes the need to define old age unnecessary. Christiane Streubel and Mone Spindler in this issue trace these shifting meanings of anti-aging medicine to the aging body.

2. Growing old has become a specific concern of medical intervention and biogerontological research. There are suggestions, however, that the increased medical knowledge and ensuing medicalisation (Conrad 2007) of aging promoted a skewed image of the aging experience as limited to the somatic decline of the body, while ignoring the array of important socio-economic and behavioural factors in experiencing old age (Powell 2006; Katz 1996). Understanding that bodies are socially and culturally constituted, several critical writers have argued that the image of aging has been further altered by a new focus on female aging (Twiggs 2003; Calasanti and Slevin 2006; Calasanti et al. 2006; Moen 2001; Estes et al. 2003a, b; Lock 1994). Barbara Marshall in this issue takes on this debate by exploring the intersection between the medicalising of old age and gender by examining the functionality of male bodies and the emergence of a "male andropause" as central to the number of age-related health problems.

3. A key element of the challenges of anti-aging cultures in biomedicine is the ethical questions that arise from its market-driven approach. These concerns are multiple and address the contested desire of life extension and the alteration and commodification of oneself ${ }^{6}$ as well as questions of social justice such as inequity and overpopulation (for example, Estes et al. 2003a, b;

\footnotetext{
${ }^{6}$ See, for example, for questions on the alteration and commodification of oneself: Turner 2004; on the natural law theory: Fukuyama 2002; on posthuman theory: Hayles 1999; Hook 2004; and on the value of life concept: Overall 2003.
} 
Olshansky et al. 2002). Scholars remain divided on these aspects, while a "consensus on the ethics of human life extension might prove elusive" (Partridge and Hall 2007), critics have argued that life extension would not outweigh the costs of serious adverse consequences for individuals, society and the environment (Fukuyama 2002). Supporters, for example, Mackey (2003), embrace anti-aging medicine on ethical grounds because they see it as potentially reducing the incidence and prevalence of many diseases and allowing for more active and healthier lives. The subject as an ethical self is directly addressed where antiaging medicine promotes that the consumerist ideal that granting the freedom to purchase antiaging medicines is advancing personal autonomy. Alan Petersen and Kate Seear critically reflect on the socio-economic dimension and anti-aging medical market driven choices, while Hans-Jörg Ehni and Georg Marckman ask whether it is possible to prevent a further increase in healthcare inequalities for the elderly.

4. The last major theme is the range of conflicting definitions of anti-aging medicine as complementary or evidence-based medicine, based upon a scientific level that widens the challenges of approaching old age. At stake is ultimately the legitimacy, course, and position of biogerontology as a valid field of inquiry, as discussed by Courtney Mykytyn's article in this issue. John Vincent, in this issue, tackles core issues such as health, death, autonomy, economic feasibility and justice, as well as the underlying question of what it means to be an aging human being, as he focuses on the tensions between the supporters and opponents of anti-aging medicine and their equally elevated emotionally responses.

The following papers engage with these themes as their authors discuss systems of knowledge production and epistemology; gender and the concept of disease; optimization and enhancement of the physical self; theory and politics of anti-aging "political economy"; and the ethics of anti-aging medicine and market consequences, as well as a critical consideration of the opponents and supporters of the approach to aging by anti-aging science and medicine.

John Vincent who as a critical gerontologist opens this special issue with a provocative review of the past and present debates that are waged between the supporters and critics of anti-aging cultures. The past decades have seen what looked like a number of significant breakthroughs in anti-aging science and its attempt to create mechanisms for the avoidance of biological aging and raising the spectre of the biomedical abolition of the need to die of old age. Vincent places the supporters of the anti-aging movement-a diverse set of people ranging from scientists at university based laboratories, corporate marketing executives to new age hippy entrepreneurs-at the boundary where anti-aging meets posthumanism: the promise of a biomedical and science technology that would ease, even remove the limitations of human bodily frailty, defined as constraints on freedom to live, by transforming human bodies into something new and better. Anti-aging critics-some of which have been from established scientists in the field of biology and gerontology and the Third age movement-deemed to be "conservative" in their moral critique, argue for a re-evaluation of the postwork phase of life. Vincent supports instead the alternative route that would see a reduction of biologisation of old age through anti-aging campaigns and end to a restriction of cultural and gender aspects to aging to achieve a culturally valued final part to life.

Courtney Mykytyn takes this debate as detailed by Vincent and refines the inherent problems that run through the anti-aging campaigns by arguing that there is a fundamental misunderstanding between anti-aging practitioners who seek to use biomedicine to effectively achieve human "immortality" (a minority position) and those opposed to such aims. Drawing up anthropological fieldwork and the report of the United State's Council on Bioethics established in 2002, Mykytyn identifies the central problem as the language and assumptions employed by each side. While governmental bioethics interpret anti-aging medicine as a quest for immortality violating human dignity by its longing to overcome death, the vast majority of anti-aging clinicians and researchers understand health and the prevention of pain as their most important motive force. For the latter, optimal health medicine and desire for life quality are the main goals of anti-aging medicine. Slowing, arresting, or reversing the aging process is positioned along the axis of health and pain rather than that of life and death. Consequently, each side in the debate works at cross purposes and true dialogue and understanding is 
lost. Mykytyn makes an important contribution by including the voices of anti-aging practitioners in the debate, concluding that there is a need to incorporate the approach of anti-aging proponents into the greater discussion and by doing so we learn that anti-aging is more than just the aim to live forever, and it is fundamentally concerned with the shifting relationships between biomedicine, health, and growing old.

These anti-aging debates have had vivid media coverage, following up on the adherents and opponents of prolonging life. Christiane Streubel and Mone Spindler challenge the commonly held belief that the media portrayed anti-aging medicine as nothing more than money-making quackery. Instead, by analyzing over 300 media presentations and employing the ethnographic technique of participant observation at German and European anti-aging medicine conference, Streubel and Spindler discovered the 'quality media' reported favorably on antiaging research and the idea of medical intervention in the biological aging process. In doing so, they establish the chronology of the anti-aging movement in the West, including the American Academy of Anti-Aging Medicine (A4M), which recommends therapies with hormones and nutritional supplements that are based on a medical theory borrowed from Olympic sports medicine, Aubrey de Grey's Methuselah Foundation, which seeks to eliminate aging altogether by fixing the problems of aging at the molecular level (genetic intervention and stem cell applications), and finally contrasting this with the German Society of Anti-Aging Medicome, which works towards what they call "age prevention" and an impairment-free life. This course of action demands a greater involvement by the individuals themselves who seek to achieve such ends through diet, nutritional supplements and a healthy life style.

Prevention and enhancement as key factors of the approach by anti-aging medicine, are examined closely by Barbara Marshall's article on the emergence of the aging male as problematic, adding a gendered reading on the medical and pharmaceutical enhancement strategies to amend aging bodies. Historically contextualizing these strategies, Marshall charts the understanding of the aging male from the nineteenthcentury association of the decline in male sex hormones with that of a decline in male economic productivity to the twenty-first century insistence that male sexual function is an indicator of male health and its lack as a warning sign of disease. Central to this construction has been the revival of a hormonal model of the male body in which anti-aging is linked to the restoration of lost masculinity. In this manner, "healthy aging" is achieved solely by late-life virility. Drawing upon a wide range of biomedical literature, as well as the work of social scientists and historians, Marshall shows how bodies were "made and remade at the intersection of science and culture" (28) and that the key variable used to understand the aging male body was male vigor as measured by male sexual function.

The persuasiveness of the anti-aging promise, or at least a reduction of side effects of aging, have created a huge market eagerly used by participants who have espoused their individual responsibility for minimizing aging. Yet, they are not acting within a vacuum. Alan Robert Petersen and Kate Seear focus on the specific politico-economic conditions giving rise to and sustaining anti-aging medicine as an area of specialist knowledge and practice and creating a global anti-aging medical industry. Through various techniques of professionalization, among others including expert networks and the strategic utilization of diverse media, proponents and practitioners were successful in consolidating anti-aging medicine's reputation as one of the central emerging industries of the twenty-first century. Petersen and Seear discuss the successfully promoted linkage of anti-aging medicine with medical key technologies such as nanotechnology, stem cells, and genetics. Tracing the large money invested "aging-related" research by Western governments and estimates of the current anti-aging marketplace, they reveal the close links between affiliations of researchers and editorial board members of key journals of anti-aging research with pharmaceutical and medical supplies companies. The current hype and promise surrounding anti-aging medicine is strengthened through news media coverage and prominent websites. Here, Petersen and Seear draw upon the "sociology of expectation", which suggest that when heightened expectations are not met economic support is withdrawn and research interests move else. They provocatively challenge the present chorus of approval for anti-aging medicine by suggesting that the present interest in anti-aging medicine is merely a 'blip' in the history of biomedical innovations: with the unavoidable disappointment that comes when technologies fall short to the public's great expectations. 
This extensive industry surrounding anti-aging and biomedicine underlies normative aspects that are still under-addressed. Hans-Jörg Ehni and Georg Marckmann discuss the crucial relation of widespread concerns over a demographic-related increase of health care costs and the promises of anti-aging cultures that modify the aging process. Concerned with the aspect of access to a socio-economic market and the interrelation with social justice, they illustrate the normative aspect of distributive justice. There is currently no empirical data on the prospective health care costs and their age related trends, however, as the authors demonstrate, it is important to discuss the resulting priorities for research in the field of biogerontology. They do so by analyzing three possible biodemographic scenarios (compressed morbidity, dynamic equilibrium, prolonged senescence), which each has certain effects on health care expenditures. They suggest researchers use the current individual spending figures for anti-aging medicine in conjunction with the estimated effects of public expenditures on aging research to meaningfully interpret the rising cost of western health care.

\section{Further Research}

The papers in this themed issue illustrate the multifaceted nature of anti-aging in the field of biomedicine and its related shifting of the meaning of old age. The approaches covered here range from the historical to the cultural, including the ethicaleconomic and the socio-economic perspectives. Ultimately, these essays raise as many questions as they answer, and in doing so indicate the very real need for further research and study of anti-aging medicine and its role in western society.

Of the many potential paths for future research, we believe there are five areas that would contribute most to our understanding of the very complex set of issues that are before us. First, what really does it mean be 'old' in the context of anti-aging medicine? We still need to know much more about what the elderly themselves want (for example, Chapman 2005; Edmondson 2005). The current anti-aging market, as illustrated by the sheer numbers of people purchasing such therapies, seems to be a case of Nikolas Rose's observation of the current trend towards " "somatic' individuals", that is, people who define themselves as biomedical entities and in need of medical intervention (Rose 2007, p. 26). How far are the potential recipients of anti-aging treatments influenced by manners of speaking that prioritize a "forever functional" (Katz and Marshall 2002) existence, including a strict commitment to health? Currently, much of the anti-aging material is derived from those who are not themselves yet old. Further studies are needed to contrast the science and biomedicine of anti-aging with those who are experiencing this "targeted" age (for example, Lucke et al. 2005).

Second, a key issue in our current discourse around the meaning of old age is that the elderly are often constructed as an undifferentiated mass with a static aging body; this discourse contributes to a falsely homogenised understanding of the aging experience. Yet old age is not a single universal state but a series of stages. Indeed, this understanding of the ageing process is centuries old, figuring into the humoural understanding of old age and a key component of those texts that mark the beginning of the western literary canon on old age and ageing (Ballenger 2006; Botelho and Thane 2000). While not completely ignored by theorists, there still is an absence of the oldest of the old in much of the current research into anti-aging medicine discourses despite the concept's venerable tradition. We hope that a renewed awareness of the different stages of old age will generate a greater and more nuanced understanding of the continuum of experience that is the modern ageing process, and one which possibly might have also potential health benefits.

Third, we need to have a better understanding of the gender dynamic involved in growing old, and in its relation to anti-aging cultures. While women have been and continue to be the largest group of the elderly, as well as the most long-lived, the discourse surrounding both anti-aging medicine and the antiaging movements themselves, is very much constructed in terms of the male body as the normative body; an image rightly questioned by critical studies (Marshall this issue; Kampf 2009; Arber et al. 2008). We still need more studies on this aspect because a gendered analysis of this issue and the materials that support it will yield exciting and thought-provoking new aspects to the debate of what it means to have a healthy old age. 
A fourth, and closely connected area, is a need for a greater sensitivity to social and economic differences found amongst the elderly. What does antiaging medicine promise to those of limited economic means? In fact, does anti-aging medicine offer anything to the socio-economically disadvantaged elderly? How does the unavailability of anti-aging medicine produce counter-effects on the health and well-being of those who are unable to afford the therapies? The issue of age and social justice cannot be ignored by the commentators, critics, or the proponents of anti-aging medicine. We hope that those engaged in the study of anti-aging medicine will be more aware of the ways in which the poor might choose to define a good old age, ways that may be fundamentally different from those of the rich.

A fifth and final area is the role of the media in forming and shaping both the elderly's sense of their selves and the role that biomedicine can and should play in the life course. It is here that perhaps all of the issues raised above converge. In what ways is the image of a healthy old age gendered? What voice are the elderly themselves afforded in the public sphere of media and markets? Are the various stages of old age represented-or can the media be held responsible for the homogenized view of aging that currently informs much of our understanding? Finally, in what ways and towards what ends are the economically empowered or disadvantaged elderly used to signify the meaning of old age?

Anti-aging medicine, including both its hype and its serious considerations, has now come to span the entire globe as its practitioners search for the root cause of a healthy old age. Within this search-and despite all the variability, flexibility and velocity of the anti-aging movements - the question of what constitutes "Old Age" remains the central issue. In some sense, we have not moved far from Binstock's recent call to leave boundary work aside and to start taking stock of the vital (and possibly more immediate) aspects of health benefits in old age (Binstock 2003, p. 12).

Clearly, as scholars, thinkers, critics, and medical practitioners we have just begun to plumb the depths of a wide range of issues that present themselves in this themed issue. We hope that these researchleading essays collected here will stimulate much interdisciplinary thought and ideas for future work at the convergence of anti-aging and biomedicine cultures.

\section{References}

Achenbaum, W.A. 1995. Crossing frontiers. Cambridge: Cambridge University Press.

Arber, Sara, Tushna Vandrevala, Tom Daly, and Sarah Hampson. 2008. Understanding gender differences in older people's attitudes towards life-prolonging medical technologies. Journal of Aging Studies 22(4): 366-375.

Ballenger, Jesse F. 2006. Self, senility, and alzheimer's disease in modern America: A history. Baltimore, Maryland: The Johns Hopkins University Press.

Binstock, Robert H. 2003. The war on 'anti-aging medicine'. Gerontologist 43(1): 4-14.

Botelho, Lynn, and Thane, Pat. 2000. Women and ageing in British society since 1500. London: Longman Publishing.

Bundesministerium für Gesundheit und Soziale Sicherung. 2004. Gesund altern. http://www.erfahrung-ist-zukunft.de/ Webs/EiZ/Content/DE/Artikel/Materialien/Anlagen/2007 1018-gesund-altern-bmg-

pdf,property=publicationFile.pdf. Accessed 25 May 2009.

Burri, Regula Valérie, and Joseph Dumit (eds.). 2007. Biomedicine as culture: Instrumental practices, technoscientific knowledge, and new modes of life. New York: Routledge.

Calasanti, Toni, and Kathleen F. Slevin (eds.). 2006. Age matters: Realigning feminist thinking. New York: Routledge.

Calasanti, Toni, Kathleen F. Slevin, and Neal King. 2006. Ageism and feminism: From "Et Cetera" to center. National Women's Association Journal 18(1): 14-30.

Chapman, Sherry Ann. 2005. Theorizing about aging well: Constructing a narrative. Canadian Journal on Aging 24(1): 9-18.

Cole, Thomas. 1992. Journey of life. Cambridge: Cambridge University Press.

Conrad, Peter. 2007. The medicalization of society. Baltimore: The Johns Hopkins University Press.

DePinho, Ronald A. 2000. The age of cancer. Nature 408: 248254.

Edmondson, Ricca. 2005. Wisdom in later life: Ethnographic approaches. Ageing and Society 25: 339-356.

Estes, Caroll, Simon Biggs, and Chris Phillipson. 2003a. Social theory, social policy and ageing: A critical introduction maidenhead. Philadelphia: Open University Press.

Estes, Caroll, Simon Biggs, and Chris Phillipson. 2003. Feminist's perspectives and old age policy. In Social theory, social policy and ageing: A critical introduction maidenhead, ed. Estes Caroll, Simon Biggs, and Chris Phillipson, 44-62. London: Open University Press.

Featherstone, Mike. 1995. Images of aging: Cultural representations of later life. New York: Routledge.

Fossel, Michael. 2003. Editorial: What ethics are these? Journal of Anti-Aging Medicine 6(2): 71. 
Fukuyama, Francis. 2002. Our posthuman future: Consequences of the biotechnology revolution. New York: Farrar, Straus \& Giroux.

Gruman, Gerald J. 1966. A history of ideas about the prolongation of life. The evolution of prolongivity hypothesis to 1800. In The American Philosophical Society.

Gubrium, Jaber F. 2005. The social worlds of old age. In Cambridge handbook of age and ageing, ed. Malcolm L. Johnson, in association with Vern L. Bengtson, Peter G. Coleman, and Thomas B. L. Kirkwood, 310-316. Cambridge: Cambridge University Press.

Haber, Carol. 2004. Life extension and history: The continual search for the fountain of youth. Journals of Gerontology 59A: 515-522.

Hayles, Katherine. 1999. How we become posthuman: Virtual bodies in cybernetics, literature and informatics. Chicago: University of Chicago Press.

Hook, C.Christopher. 2004. Transhumanism and posthumanism. In The encyclopedia of bioethics, ed. S.G. Post, 2517-2520. New York: Macmillan Reference.

Huxley, Aldous. 1932. Brave new world. London: Chatto \& Windus.

Kampf, Antje. 2009. The absence of Adam: prostate cancer and male identity. In Aging and identity: A postmodern dialogue, ed. Jason Powell and Tony Gilbert. New York: Nova Science Publishers.

Katz, Stephen. 1996. Disciplining old age. The formation of gerontological knowledge. Charlottesville, VA: Virginia University Press.

Katz, Stephen. 2005. Cultural aging: Life course, lifestyle, and senior worlds. Toronto: University of Toronto Press.

Katz, Stephen, and Barbara L. Marshall. 2002. Forever functional: Male sexual fitness and the aging body. Body \& Society 8: 43-70.

Katz, Stephen, and Kevin Peters. 2008. Enhancing the mind? Memory medicine, dementia and the aging brain. Journal of Aging Studies 22(4): 348-355.

Lankester, Edwin Ray. 1870. On comparative longevity in man and the lower animals. London: Macmillan.

Lock, Margaret. 1994. Encounters with aging mythologies of menopause in Japan and North America. Berkeley: University of California Press.

Lucke, Jayne C., and W. Hall. 2005. Who wants to live forever? Embo Reports 6(2): 98-102.

Lucke, Jayne C., Phillippa C. Diedrichs, Bradley Partridge, and Wayne D. Hall. 2009. Anticipating the anti-ageing pill. Lessons from the history of the oral contraceptive pill and hormone replacement therapy. EMBO Reports 10(2): 108-113.
Mackey, T. 2003. An ethical assessment of anti-aging medicine. Journal of Anti-Aging Medicine 6(3): 187-204. doi: 10.1089/109454503322733045.

Moen, Phyllis. 2001. The gendered life course. In Handbook of aging and social sciences, ed. H. Binstock Robert, and Linda George, 179-196. San Diego: Academic Press.

Nasher, Leo Ignatz. 1919. [1914] Geriatrics: The diseases of old age and their treatment. London: Kegan Paul, French, Trubner \& Co.

Olshansky, S., Leonard Hayflick Jay, and Bruce Carnes. 2002. Position statement on human aging. Journals of Gerontology 57a(8): B292-B297.

Overall, Christine. 2003. Aging, death and human longetivity: A philosophical inquriy. Berkeley: University of California Press.

Partridge, Brad, and Wayne Hall. 2007. The search for methuselah. Should we endeavour to increase the maximum human lifespan? EMBO Reports 8(10): 888-891.

Paul, Norbert W. 2009. Editorial: Making medicine studies: Exploring interplays of medicine, science, technology, and society beyond disciplinary confines. Medicine Studies. doi: 10.1007/s12376-009-0006.

Powell, Jason L. 2006. Occidental modernity, the biomedical gaze and aging. In Social theory and aging, ed. Jason L. Powell, 17-42. Toronto: Rowman \& Littlefield Publishers.

Robinson, Nichols. 1725. A new theory of physick and diseases founded on newtonian philosophy. London: C. Rivington, J. Lacy and J. Clark.

Rose, Nikolas. 2007. The politics of life itself: Biomedicine, power, and subjectvity in the twenty-first century. Princeton and Oxford: Princeton University Press.

Sengoopta, Chandak. 2006. The most secret quintessence of life: Sex, glands, and hormones, 1850-1950. Chicago: University of Chicago Press.

Stoff, Heiko. 2004. Ewige Jugend: Konzepte der Verjüngung vom späten neunzehnten Jahrhundert bis ins Dritte Reich. Köln: Böhlau.

Turner, Leigh. 2004. Biotechnology, bioethics and anti-aging interventions. Trends in Biotechnology 22(5): 219-221.

Twigg, Julia. 2003. The body, gender, and age: Feminist insights in social gerontology. Journal of Aging Studies 18(1): 59-73.

Vincent, John. 2003. Old age. London: Routledge.

Vincent, John, Emanuelle Tulle, and John Bond. 2008. Editorial: The anti-ageing enterprise: science, knowledge, expertise, rhetoric and values. Journal of Aging Studies 22(4): 340-347. 